\title{
Anthropologists rocked by fossil access row
}

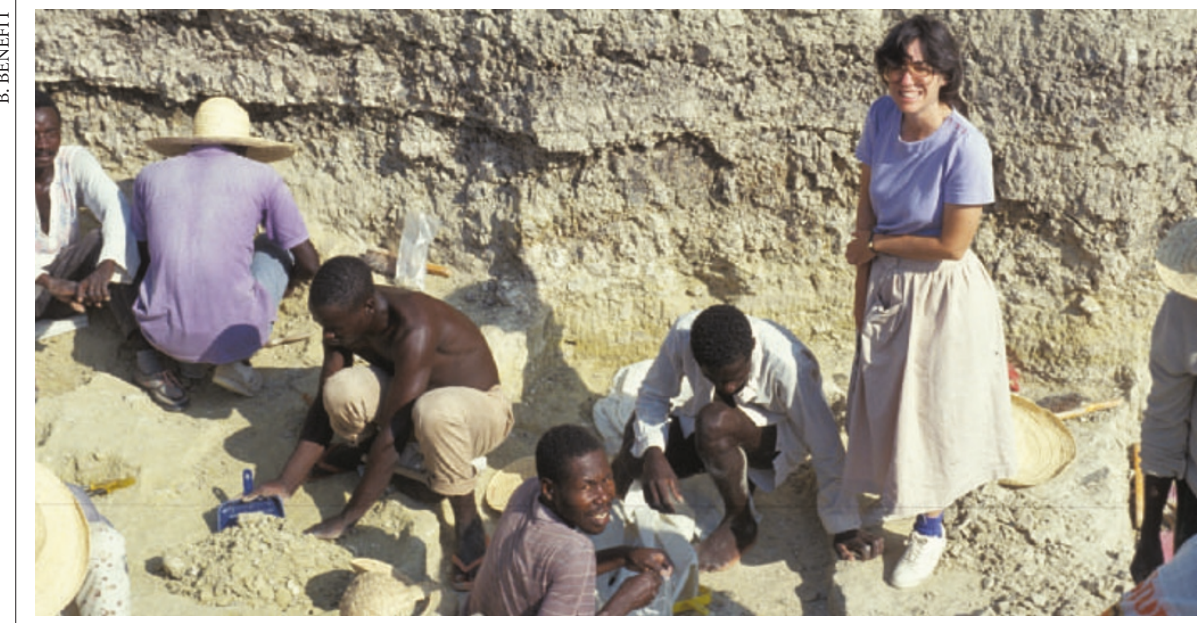

Brenda Benefit (right) wants to analyse fossils fully before sharing data with lab-based colleagues.

\section{Rex Dalton, San Diego}

Palaeoanthropologists are falling out over who should have access to data on the most prized fossils of our human ancestors, once they have been discovered in the field.

The National Science Foundation (NSF), which funds most work in the discipline by US researchers, is preparing guidelines on when and how data should be released for general analysis by researchers other than those who find the fossils.

But the community is bitterly divided over what the rules should say. Those who discover hominids during expeditions, often in Africa, want to keep first rights to analyse and document their work. But those who do analytical work at universities say the discipline would benefit if all photographs and measurements were made openly available as soon as possible after discovery.

Among those wanting quicker access to the fossil data is Ian Tattersall, anthropology curator at the American Museum of Natural History in New York City. "If you are taking public money to go out and find fossils, you have to make them available," he says.

But Brenda Benefit, a palaeoanthropologist at New Mexico State University in Las Cruces, thinks that such access would take advantage of field research teams who spend years in dangerous conditions investigating sites. "I find it appalling that scientists who make no such commitment wish to gain from the personal sacrifices of others," she says.

Mark Weiss and John Yellen, two NSF officials responsible for physical anthropology and archaeology, respectively, have been working on the guidelines since last year. They are reviewing about 80 letters from researchers received in response to a request for comments, and expect to produce final guidelines later this year, but they are treading carefully."I have tried to be as equitable and reasonable as possible," says Weiss.

Some researchers say that the pair are relying too heavily for advice on Harvard palaeoanthropologist David Pilbeam, who has helped to process the researchers' comments, and whom critics regard as averse to fieldwork. In a day-long trek in Pakistan many years ago, Pilbeam wouldn't leave the truck "to walk 50 metres to a rich hominid site", says Martin Pickford, a palaeoanthropologist at the National Museum of Natural History in Paris. "He told me he didn't like wide-open spaces."

Pilbeam acknowledges that he doesn't care for fieldwork but says this won't affect his advisory role at the NSF. Weiss says that Pilbeam is "as objective as anyone could be".

When hominids are discovered, their skulls, teeth and major bones are often encased in stone and shattered into hundreds of pieces. These must be painstakingly separated from the rock and pieced together, which can take years.

Researchers typically report a new hominid species or genus in a short report in publications such as Nature or Science after most of the reconstruction is done, and then publish a much fuller analysis in a lengthy, definitive monograph some years later.

Tattersall, who wants data for the books he publishes on hominids, says researchers should have full access to the specimens immediately after initial publication.

But Timothy White, a palaeoanthropologist at the University of California, Berkeley, whose team has made some of the biggest discoveries in Ethiopia, disagrees. "We don't think laboratory workers or book publishers should dictate our publication schedule," he says. "We're the ones who seek, find, clean, restore and study the fossils, and put them into context."

The NSF's task is complicated by the question of whether it should even be publishing guidelines on the handling of specimens that belong to the nation where they are found, such as Ethiopia or Kenya. Museums there often demand approval from the discoverer before they grant other researchers access.

\section{Gates grant helps Africa develop science academies}

\section{Declan Butler}

The Bill \& Melinda Gates Foundation has boosted science in Africa by making a US\$20 million grant to help build independent scientific academies on the continent.

The money, which will be distributed by the US National Academies, will be used to train staff in African academies to organize research and conferences, to network with governments and other institutions, to use computers and to raise funds.

The Seattle-based Gates foundation hopes that the initiative will help African scientists to influence countries' policies on public health, agriculture and the environment.
"The ultimate goal of this initiative is to help each participating academy achieve, by the end of a ten-year period, a welldeveloped and enduring capacity to provide credible policy advice for its nation," says Bruce Alberts, president of the National Academy of Sciences.

The US National Academies will later this year select three science academies in Africa as lead partners for the initiative. The money will also support an alliance of African science academies, which will hold symposia and run collaborative workshops.

The grant is "tremendous news", says Mohamed Hassan, president of the Nairobi- based African Academy of Sciences and director of the Trieste-based Third World Academy of Sciences.

Hassan, who was born in Sudan, says the challenge is to modernize Africa's academies and transform them from "clubs for old men" to younger, more active and inclusive bodies that can help to build scientific capacity and address the continent's problems.

Africa's population is rapidly approaching 1 billion, but fewer than 30,000 African-born PhD-level scientists work there, and currently independent scientific academies operate in only ten of the continent's 53 countries. 